\title{
Effect of Postoperative Radiotherapy In Women With Localized Pure Mucinous Breast Cancer After Lumpectomy: A Population-Based Study
}

\section{QiuPing Mo}

Zhejiang Provincial People's Hospital

\section{Yongzhen Wang}

Zhejiang University School of Medicine Second Affiliated Hospital

JinLan Shan

Zhejiang University School of Medicine Women's Hospital

Xiaochen Wang ( $\nabla$ wangxiaochen@zju.edu.cn )

Zhejiang University

\section{Research}

Keywords: Breast neoplasm, Radiotherapy, adjuvant, Mastectomy, segmental, Prognosis, Mucinous

Posted Date: July 7th, 2021

DOI: https://doi.org/10.21203/rs.3.rs-670432/v1

License: (c) (i) This work is licensed under a Creative Commons Attribution 4.0 International License. Read Full License 


\section{Abstract}

\section{Purpose}

Pure mucinous breast cancer $(\mathrm{PMBC})$ is a rare subtype of invasive breast cancer with favorable prognosis, in which the effect of postoperative radiotherapy remains unclear. We aimed to investigate the prognostic value of postoperative radiotherapy in women with localized PMBC after lumpectomy.

\section{Methods}

We conducted a retrospective cohort study to compare the effectiveness of postoperative radiotherapy (RT) and omitting postoperative radiotherapy (non-RT) in patients with first primary T1-2N0M0 $(\mathrm{T} \leq 3 \mathrm{~cm})$ PMBC who underwent lumpectomy between 1998 and 2015 using the Surveillance, Epidemiology, and End Results (SEER) database. Breast cancer-specific survival (BCSS) was compared between RT and non-

RT groups using Kaplan-Meier method and Cox proportional hazards regression model. Propensity score matching (PSM) was carried out to balance cohort baselines. In addition, an exploratory analysis was performed to verify the effectiveness of RT in subgroup patients.

\section{Results}

Overall, 5352(68.2\%) and 2494(31.8\%) eligible patients with tumor size $\leq 3 \mathrm{~cm}$ localized PMBC received lumpectomy with postoperative RT and lumpectomy without postoperative RT respectively. The median follow-up duration was 92 months. The 15-year BCSS was $94.39 \%$ (95\% Cl, 93.08\% to $95.35 \%$ ) in the RT group versus $91.38 \%(95 \% \mathrm{Cl}, 88.86 \%$ to $93.35 \%)$ in the non-RT group $(P<0.001)$. The adjusted hazard ratio for BCSS was $0.64(95 \% \mathrm{Cl}, 0.49$ to $0.84 ; P=0.001)$ for RT group versus non-RT group. After PSM, similar results were yielded. Adjuvant RT reduced the 15-year risk of breast cancer death from $7.92 \%$ to $6.15 \%(P=0.039)$. The adjusted hazard ratio for BCSS were $0.66(95 \% \mathrm{Cl}, 0.47$ to $0.92 ; P=0.014)$ for RT group versus non-RT group. The benefit of RT was well consistent across all subgroups.

\section{Conclusion}

Among women with T1-2N0M0 (tumor size $\leq 3 \mathrm{~cm}$ ) PMBC, the addition of RT after lumpectomy was significantly associated with a reduced incidence of breast cancer death compared with non-RT, and the magnitude of benefit may be modest. This suggests that postoperative RT is recommended in the treatment of localized PMBC.

\section{Introduction}

Mucinous breast carcinoma (MBC) accounting for approximately 1 to $6 \%$ of all breast cancer is divided into two pathological subtypes: pure mucinous breast cancer (PMBC) and mix mucinous breast carcinoma (MMBC) (1). PMBC exclusively consists of tumor tissue with extracellular mucin production over $90 \%$, whereas MMBC usually mixes infiltrating ductal epithelial component with mucinous areas covering from $50-90 \%(2)$. The comparisons of biological features and clinical prognosis have been 
identified previously among PMBC, MMBC and invasive breast cancer of no special type (1,3-13). PMBC usually occurs in elderly patients, especially in postmenopausal women(8). The tumor size of PMBC ranges from less than $1 \mathrm{~cm}$ to more than $20 \mathrm{~cm}$, with an average of $3 \mathrm{~cm}(14)$. On account of fewer genetic mutations, PMBC has a stabilized luminal A phenotype with higher expression of hormone receptor and a lower rate of positive human epidermal growth factors 2 (HER-2) $(5,15,16)$. A mechanical barrier made of abundant pools of extracellular mucus around cellular island restricts carcinoma cell invasion, leading to less axillary lymph node or distant metastases. Axillary node involvement, although rare, appears to be the worst prognostic factor followed by tumor size, age, progesterone receptor(PR), HER-2 status and nuclear grade $(3,17-20)$. It has reported that the 5-year, 10-year disease-free survival (DFS) were up to 94\%(1), 92\%(9) for patients with node-negative PMBC, respectively. Hence, PMBC presents distinct clinicopathological characteristics with especially favorable prognosis.

At present, the recommendations of locoregional treatment for patients with operable PMBC from the latest National Comprehensive Cancer Network are the same as that for patients with typical breast cancer. However, it is difficult to evaluate the effect of local regional treatment on survival outcome in prospective cohort studies or randomized trials owing to the relatively low incidence rate and a limited follow-up prognosis of PMBC. Guidelines on radiotherapy of PMBC are extrapolated from evidence based on other common invasive breast cancer. Although scholars have done some retrospective studies, the effect of postoperative radiotherapy in patiens with PMBC is uncertain so far. Previous study showed that adjuvant radiotherapy was an independent protective factor for both overall survival(OS) and BCSS in patients with PMBC. However, this retrospective study was hetetogeneous in nature because inclusion criteria involved in advanced patients, and the surgical treatment before radiotherapy involved in mastectomy and lumpectomy. A recent SEER research presented that postoperative radiotherapy following lumpectomy improved the 10-year BCSS rates from $94.5-97.6 \%$ in patients aged $\geq 65$ years diagnosed with T1-2N0 and hormone receptor-positive PMBC. Yet regrettably, patients aged $<65$ years were not included in this study. Besides, patients with tumor size larger than $3 \mathrm{~cm}$ were more likely to receive endocrine therapy, which may confuse results(21). Obviously, it is necessary to adequately assess individualized roles of postoperative RT in this special subtype of breast carcinoma. Hence, we proceeded to a large population-based study using SEER to investigate the effect of postoperative RT on BCSS in women undergoing lumpectomy with T1-2NOM0 (tumor size $\leq 3 \mathrm{~cm}$ ) stage PMBC.

\section{Methods}

\section{Patients population}

This retrospective study was performed utilizing the Surveillance, Epidemiology, and End Results (SEER) database (November 2018 submission) which released cancer data from 18 registries of national cancer institute and covered approximately $28 \%$ of the US population(22). A case-listing session was derived from SEER ${ }^{\star}$ Stat version 8.3.5. 
We selected all female cases of histological diagnosed first primary PMBC with the International Classification of Diseases for Oncology, 3rd Revision (ICD-0-3) code 8480/3 from January 1998 through December 2015. Patients with T1-2N0M0 (tumor size less than 3 centimeters) stage who received lumpectomy with or without beam postoperative RT were included in the cohort. The exclusion criteria were listed as follows: diagnosed from death certificate or autopsy only; no active or complete follow-up data; unknown T, N, M stage; with nodal positive disease or metastases disease at diagnosis; without operation or unknown surgery; unknown RT; non-beam RT; non-postoperative radiotherapy; bilateral cancer or unknown laterality; unknown tumor size. The flowchart for patient selection was shown in Fig. 1.

\section{Study Covariates}

According to administrations of lumpectomy and postoperative RT, a total of 7846 eligible patients under the inclusion criteria were stratified into RT group and non-RT group. We subsequently reviewed variable information of each case on patient baseline demographics, such as age at diagnoses, year of diagnoses, race, marital status at diagnoses. Then, tumor clinicopathological characteristics, including tumor laterality, tumor grade, T stage, tumor size, estrogen receptor (ER) and progesterone receptor (PR) status, were extracted. Among them, the T stage was adjusted by the 6th American Joint Committee on Cancer (AJCC) TNM Staging System. Tumor grade was categorized into four levels on the biasis of the degree of differentiation: grade I, well differentiated; grade II, moderately differentiated; grade III, poorly differentiated; grade IV, undifferentiated or anaplastic. Borderline ER/PR status defined as having 1-10\% positivity by immunohistochemistry were merged into positive ER/PR status $(23,24)$. In this study, we did not evaluate HER-2 status because of lacking data before 2010.

\section{Statistical Analysis}

Categoric variables were compared across treatment groups using the Pearson chi-squared test, and continuous variables were analyzed by two independent sample t-tests or Wilcoxon rank sum test. The primary endpoint of this study was breast cancer-specific survival (BCSS). BCSS was defined as an interval from the data of PMBC diagnosis to death as a result of breast cancer. Using Kaplan-Meier survival analysis, BCSS were estimated with log-rank tests in unmatched groups and matched groups. Hazard Ratio $(\mathrm{HR})$ and $95 \%$ confidence interval $(95 \% \mathrm{Cl})$ were calculated by Cox proportional hazards model to estimate the effect of RT. The multivariable Cox proportional hazards regression analysis incorporated variables that were significant or approximately significant in univariate analyses. The proportional-hazards assumption was checked based on Schoenfeld residuals after fitting a Cox model. And all of the Cox models obeyed the proportional risk hypothesis. PMS method was used to control confounding bias in the retrospective study. Propensity scores of being receipt of RT were calculated by using a multivariable logistic regression model. The independent variables are being those that were statistically significant for correlation with treatment modality. Patients treated with RT were matched 1:1 to patients managed without RT on propensity scores by using nearest neighbor matching algorithm. The 
threshold value of Caliper matching was set to 0.2. A standardized difference of less than 0.1 was considered an indifferent imbalance between comparison groups. Further, exploratory analysis and tests of interaction were undertaken to evaluate the effect of adjuvant RT among subgroups according to patient and tumor characteristics.

Statistical analyses were performed with SPSS, version 24.0 (SPSS Inc., Chicago, IL, USA) and STATA, version 15 (Stata Corp., College Station, TX, USA). Two-tailed $P<0.05$ was considered statistically significant.

\section{Results}

\section{Patient demographics and tumor characteristics}

Comparisons of patient demographics and tumor characteristics between RT and non-RT group were summarized in Table 1. A total of 7846 eligible patients with PMBC were identified in the cohort (mean [SD] age, 67.1 [13.3] years), of whom 5352 (68.2\%) received lumpectomy and postoperative RT, 2494 $(31.8 \%)$ were treated with lumpectomy without RT. Among patients underwent lumpectomy, those who received RT were on average 9 years younger than those who did not $(P<0.001)$. The proportion of patients receiving radiotherapy fluctuated around $70 \%$ each year (Fig. 2). The main pathological feature of patients was hormone receptor positive and well differentiated. As such, the majority of patients (92.3\%) did not receive chemotherapy. There was no significant difference between treatment groups in tumor size $(P=0.433)$. In order to eliminate the imbalance between groups that may affect results, PMS was subsequently conducted. After PMS between the RT group and non-RT group, 2149 pairs were generated. The distribution of covariates was well balanced between propensity-matched groups (Table 2).

Table 1. Demographic and tumor characteristics among all patients with pure mucinous breast cancer. 


\begin{tabular}{|c|c|c|c|c|c|}
\hline & \multicolumn{2}{|l|}{ RT } & \multicolumn{3}{|c|}{ Non-RT } \\
\hline Characteristics & No. & $\%$ & No. & $\%$ & $P^{*}$ \\
\hline Patients & 5352 & 68.2 & 2494 & 31.8 & \\
\hline \multicolumn{6}{|c|}{ Age of diagnosis, years } \\
\hline Mean (SD) & \multicolumn{2}{|c|}{$64.4(12.5)$} & \multicolumn{2}{|c|}{ 72.8(13.3) } & $<0.001$ \\
\hline Median (IQR) & \multicolumn{2}{|c|}{$66.0(56.0-74.0)$} & \multicolumn{2}{|c|}{$76.0(65.0-83.0)$} & $<0.001$ \\
\hline$<50$ & 749 & 14.1 & 197 & 7.9 & $<0.001$ \\
\hline $50-59$ & 1008 & 18.8 & 234 & 9.4 & \\
\hline $60-69$ & 1495 & 27.9 & 388 & 15.6 & \\
\hline$\geq 70$ & 2100 & 39.2 & 1675 & 67.1 & \\
\hline \multicolumn{6}{|l|}{ Era of diagnosis } \\
\hline 1998-2004 & 2027 & 37.9 & 847 & 34.0 & \multirow[t]{3}{*}{0.002} \\
\hline 2005-2009 & 1515 & 28.3 & 777 & 31.1 & \\
\hline 2010-2015 & 1810 & 33.8 & 870 & 34.9 & \\
\hline \multicolumn{6}{|l|}{ Race } \\
\hline White & 4292 & 80.2 & 2089 & 83.8 & \multirow[t]{4}{*}{$<.001$} \\
\hline Black & 453 & 8.5 & 226 & 9.1 & \\
\hline Other ${ }^{a}$ & 602 & 11.3 & 179 & 7.2 & \\
\hline \multicolumn{5}{|l|}{ Marital status } & \\
\hline Married & 2892 & 54.0 & 989 & 39.6 & \multirow[t]{3}{*}{$<0.001$} \\
\hline Non-married ${ }^{\mathrm{b}}$ & 680 & 12.7 & 262 & 10.5 & \\
\hline DSWC & 1680 & 30 & 1109 & 44.5 & \\
\hline Unknown & 172 & 3.2 & 134 & 5.4 & \\
\hline \multicolumn{6}{|l|}{ Laterality } \\
\hline Left & 2782 & 52.0 & 1321 & 53.0 & \multirow[t]{2}{*}{0.415} \\
\hline Right & 2570 & 48.0 & 1173 & 47.0 & \\
\hline \multicolumn{6}{|c|}{ Tumor size ( $T$ stage), cm } \\
\hline Mean (SD) & $1.4(0.7$ & & $1.4(0.7$ & & 0.092 \\
\hline Median (IQR) & $1.3(0.9$ & & $1.3(0.9$ & & 0.139 \\
\hline
\end{tabular}




\begin{tabular}{|c|c|c|c|c|c|}
\hline$\leq 1.0(\mathrm{~T} 1)$ & 2034 & 38.0 & 910 & 36.5 & \multirow[t]{3}{*}{0.433} \\
\hline $1.1-2.0(\mathrm{~T} 1)$ & 2456 & 45.9 & 1174 & 47.1 & \\
\hline 2.1-3.0 (T2) & 862 & 16.1 & 410 & 16.4 & \\
\hline \multicolumn{6}{|l|}{ Tumor grade } \\
\hline I & 2977 & 55.6 & 1376 & 55.2 & \multirow[t]{5}{*}{0.002} \\
\hline II & 1478 & 27.6 & 629 & 25.2 & \\
\hline III & 135 & 2.5 & 52 & 2.1 & \\
\hline IV & 8 & 0.2 & 4 & 0.2 & \\
\hline unknown & 754 & 14.1 & 433 & 17.4 & \\
\hline \multicolumn{6}{|l|}{ ER status } \\
\hline Positive & 5002 & 93.5 & 2187 & 87.7 & \multirow[t]{3}{*}{$<0.001$} \\
\hline Negative & 88 & 1.6 & 31 & 1.2 & \\
\hline Unknown & 262 & 4.9 & 276 & 11.1 & \\
\hline \multicolumn{6}{|l|}{ PR status } \\
\hline Positive & 4503 & 84.1 & 1964 & 78.7 & \multirow[t]{3}{*}{$<0.001$} \\
\hline Negative & 510 & 9.5 & 207 & 8.3 & \\
\hline Unknown & 339 & 6.4 & 323 & 13.0 & \\
\hline \multicolumn{6}{|l|}{ Chemotherapy } \\
\hline No/Unknown & 4854 & 90.7 & 2385 & 95.6 & \multirow[t]{2}{*}{$<0.001$} \\
\hline Yes & 498 & 9.3 & 109 & 4.4 & \\
\hline \multicolumn{6}{|c|}{$\begin{array}{l}\text { *Categoric variables were analyzed by the Pearson } x^{2} \text { test, and continuous variables (age, tumor size) } \\
\text { were analyzed by the } t \text { tests or Mann-Whitney tests. }\end{array}$} \\
\hline \multicolumn{6}{|c|}{ ancluding Asian or Pacific Islander, American Indian, Alaska Native and unknown race. } \\
\hline \multicolumn{6}{|c|}{ b'Including unmarried or domestic partner, single (never married). } \\
\hline \multicolumn{6}{|c|}{ 'Including divorced, separated and widowed. } \\
\hline $\begin{array}{l}\text { Abbreviation: } \\
\text { separated and }\end{array}$ & $\begin{array}{l}\text { therapy } \\
\text { d. }\end{array}$ & dard de & $\mathrm{R}$, interq & ge; DS & \\
\hline
\end{tabular}

Table 2. Demographic and tumor characteristics among propensity-matched population with pure mucinous breast cancer. 


\begin{tabular}{|c|c|c|c|c|c|}
\hline & RT & & Non-RT & & standardized difference \\
\hline Characteristics & No. & $\%$ & No. & $\%$ & \\
\hline Patients & 2149 & 50.0 & 2149 & 50.0 & \\
\hline \multicolumn{6}{|c|}{ Age of diagnosis, years } \\
\hline Mean (SD) & 70(11.9) & & 71(12.9) & & 0.081 \\
\hline$<50$ & 163 & 7.6 & 194 & 9.0 & 0.050 \\
\hline $50-59$ & 233 & 10.8 & 232 & 10.8 & 0.000 \\
\hline $60-69$ & 463 & 21.5 & 380 & 17.7 & 0.096 \\
\hline$\geq 70$ & 1290 & 60.0 & 1343 & 62.5 & 0.051 \\
\hline \multicolumn{6}{|l|}{ Era of diagnosis } \\
\hline 1998-2004 & 792 & 36.9 & 731 & 34.0 & 0.061 \\
\hline 2005-2009 & 585 & 27.2 & 673 & 31.3 & 0.090 \\
\hline 2010-2015 & 772 & 35.9 & 745 & 35.3 & 0.011 \\
\hline \multicolumn{6}{|l|}{ Race } \\
\hline White & 1769 & 82.3 & 1782 & 82.9 & 0.015 \\
\hline Black & 186 & 8.7 & 202 & 9.4 & 0.026 \\
\hline Other & 194 & 9.0 & 165 & 7.7 & 0.047 \\
\hline \multicolumn{6}{|l|}{ Marital status } \\
\hline Married & 932 & 43.3 & 956 & 44.5 & 0.022 \\
\hline Non-married & 215 & 10.0 & 227 & 10.6 & 0.020 \\
\hline DSW & 902 & 42.0 & 880 & 40.9 & 0.022 \\
\hline Unknown & 100 & 4.7 & 86 & 4.0 & 0.033 \\
\hline \multicolumn{6}{|l|}{ Laterality } \\
\hline Left & 1124 & 52.3 & 1139 & 53.0 & 0.014 \\
\hline Right & 1025 & 47.7 & 1010 & 47.0 & 0.014 \\
\hline \multicolumn{6}{|c|}{ Tumor size ( $T$ stage), $\mathrm{cm}$} \\
\hline Mean (SD) & $1.4(0.7)$ & & $1.4(0.7)$ & & 0.000 \\
\hline$\leq 1.0(\mathrm{~T} 1)$ & 817 & 38.0 & 822 & 38.3 & 0.006 \\
\hline $1.1-2.0(\mathrm{~T} 1)$ & 985 & 45.8 & 1009 & 47.0 & 0.024 \\
\hline
\end{tabular}




\begin{tabular}{|lccccc|}
\hline 2.1-3.0 (T2) & 347 & 16.1 & 318 & 14.8 & 0.036 \\
\hline Tumor grade & & & & & \\
\hline I & 1164 & 54.2 & 1212 & 56.4 & 0.044 \\
\hline II III & 566 & 26.3 & 558 & 26.0 & 0.007 \\
\hline IV & 45 & 2.1 & 46 & 2.1 & 0.000 \\
\hline unknown & 4 & 0.2 & 4 & 0.2 & 0.000 \\
\hline ER status & 370 & 17.2 & 329 & 15.3 & 0.052 \\
\hline Positive & & & & & \\
\hline Negative & 1912 & 89.0 & 1952 & 90.8 & 0.060 \\
\hline Unknown & 34 & 1.6 & 30 & 1.4 & 0.012 \\
\hline PR status & 203 & 9.4 & 167 & 7.8 & 0.058 \\
\hline Positive & & & & & \\
\hline Negative & 1732 & 80.6 & 1754 & 81.6 & 0.027 \\
\hline Unknown & 182 & 8.5 & 186 & 8.7 & 0.005 \\
\hline Chemotherapy & 235 & 10.9 & 209 & 9.7 & 0.039 \\
\hline No/Unknown & & & & & \\
\hline Yes & 2019 & 94.0 & 2040 & 94.9 & 0.039 \\
\hline Abbreviation: RT, radiotherapy SD, standard deviation; DSW, divorced, separated and widowed. \\
\hline
\end{tabular}

\section{Survival analyses of BCSS}

Overall, the median follow-up time was 92 months (rang, 0-227 months), and 239 breast cancer-special deaths were observed. The Kaplan-Meier survival estimate showed that 5-year, 10-year, 15-year BCSS rates were $99.01 \%$ (95\% Cl, 98.68-99.26\%), 96.95\% (95\% Cl, 96.29-97.49\%), 94.39\% (95\% Cl, 93.0895.35\%) for patients treated with RT respectively, whereas the corresponding were $97.31 \%(95 \% \mathrm{Cl}, 96.48-$ 97.94\%), 94.43\% (95\% Cl, 93-95.56\%), 91.38\%(95\% Cl, 88.86-93.35\%) for non-RT respectively. The difference between RT and non-RT curve was statistically significant (log-rank test, $P<0.001$; Fig. 3A). The univariate Cox proportional hazards regression model showed the HR of BCSS for RT versus non-RT was $0.52(95 \% \mathrm{Cl}, 0.40$ to $0.67 ; P<0.001)$. For the purpose of controlling the potential confounding factors in adjuvant RT effectiveness, the multivariable Cox proportional hazards regression analysis was further applied. After the prognostic analysis was adjusted for the following clinicopathological parameters: tumor size, tumor grade, PR status, age at diagnosis, race and married status, we observed 
postoperative RT was independently associated with better BCSS benefit (adjusted $\mathrm{HR}, 0.64 ; 95 \% \mathrm{Cl}, 0.49$ to $0.84 ; P=0.001)$. Moreover, the results also indicated that larger tumor size, age $\geq 70$ years, negative PR expression and DSW (divorced, separated, widowed) marital status were risk predictors which independently associated with BCSS(Table 3).

Table 3. Univariate and multivariate prognostic analyses of BCSS in all patients. 


\begin{tabular}{|c|c|c|c|c|c|c|}
\hline \multirow[t]{2}{*}{ Characteristics } & \multicolumn{3}{|c|}{ Univariate } & \multicolumn{3}{|c|}{ ultivariate } \\
\hline & $\mathrm{HR}$ & $95 \% \mathrm{Cl}$ & $P$ & $\mathrm{aHR}$ & $95 \% \mathrm{Cl}$ & $P$ \\
\hline \multicolumn{7}{|c|}{ Treatment groups } \\
\hline Non-RT & 1.00 & & & 1.00 & & \\
\hline RT & 0.52 & $0.40-0.67$ & $<0.001$ & 0.64 & $0.49-0.83$ & 0.001 \\
\hline \multicolumn{7}{|c|}{ Age of diagnosis, years } \\
\hline$<50$ & 1.00 & & & 1.00 & & \\
\hline $50-59$ & 1.08 & $0.58-2.03$ & 0.803 & 1.11 & $0.62-2.20$ & 0.746 \\
\hline $60-69$ & 1.46 & $0.83-2.57$ & 0.192 & 1.51 & $0.91-2.88$ & 0.166 \\
\hline$\geq 70$ & 3.51 & $2.12-5.80$ & $<0.001$ & 3.05 & $2.06-5.73$ & $<0.001$ \\
\hline \multicolumn{7}{|c|}{ Era of diagnosis } \\
\hline 1998-2004 & 1.00 & & & & & \\
\hline 2005-2009 & 1.04 & $0.77-1.41$ & 0.789 & & & \\
\hline 2010-2015 & 0.88 & $0.55-1.41$ & 0.606 & & & \\
\hline \multicolumn{7}{|l|}{ Race } \\
\hline White & 1.00 & & & 1.00 & & \\
\hline Black & 1.49 & $1.00-2.18$ & 0.047 & 1.44 & $0.95-2.12$ & 0.076 \\
\hline Other & 0.52 & $0.30-0.91$ & 0.022 & 0.70 & $0.38-1.20$ & 0.213 \\
\hline \multicolumn{7}{|l|}{ Marital status } \\
\hline Married & 1.00 & & & 1.00 & & \\
\hline Non-married & 0.92 & $0.56-1.51$ & 0.736 & 0.98 & $0.59-1.61$ & 0.931 \\
\hline DSW & 2.25 & $1.71-2.96$ & $<.001$ & 1.56 & $1.17-2.08$ & 0.002 \\
\hline Unknown & 1.90 & $1.02-3.54$ & 0.045 & 1.36 & $0.72-2.56$ & 0.339 \\
\hline \multicolumn{7}{|l|}{ Laterality } \\
\hline Left & 1.00 & & & & & \\
\hline Right & 0.95 & $0.74-1.23$ & 0.690 & & & \\
\hline \multicolumn{7}{|c|}{ Tumor size (T stage), cm } \\
\hline$\leq 1.0(\mathrm{~T} 1)$ & 1.00 & & & 1.00 & & \\
\hline $1.1-2.0(\mathrm{~T} 1)$ & 1.85 & $1.35-2.53$ & $<0.001$ & 1.92 & $1.40-2.63$ & $<.001$ \\
\hline
\end{tabular}




\begin{tabular}{|c|c|c|c|c|c|c|}
\hline $2.1-3.0$ (T2) & 2.95 & $2.05-4.24$ & $<0.001$ & 3.02 & $2.09-4.36$ & $<.001$ \\
\hline \multicolumn{7}{|l|}{ Tumor grade } \\
\hline I & 1.00 & & & 1.00 & & \\
\hline ॥ & 1.35 & $1.00-1.82$ & 0.049 & 1.31 & 0.97-1.77 & 0.079 \\
\hline III/IV & 1.95 & $1.05-3.63$ & 0.034 & 1.91 & $1.02-3.59$ & 0.043 \\
\hline unknown & 1.20 & $0.85-1.68$ & 0.305 & 1.16 & $0.83-1.64$ & 0.390 \\
\hline \multicolumn{7}{|l|}{ ER status } \\
\hline Positive & 1.00 & & & & & \\
\hline Negative & 1.65 & $0.78-3.53$ & 0.120 & & & \\
\hline Unknown & 1.24 & $0.83-1.85$ & 0.300 & & & \\
\hline \multicolumn{7}{|l|}{ PR status } \\
\hline Positive & 1.00 & & & 1.00 & & \\
\hline Negative & 1.56 & $1.08-2.26$ & 0.020 & 1.47 & $1.01-2.13$ & 0.045 \\
\hline Unknown & 1.37 & $0.95-1.98$ & 0.100 & 1.47 & $0.82-1.72$ & 0.368 \\
\hline \multicolumn{7}{|l|}{ Chemotherapy } \\
\hline No/Unknown & 1.00 & & & & & \\
\hline Yes & 0.75 & $0.46-1.21$ & 0.460 & & & \\
\hline
\end{tabular}

In the propensity-matched cohort, the survival analysis of BCSS also showed a significant difference between the two groups (log-rank test, $P=0.039$; Fig. 3B). The BCSS rate for RT group was marginally better than non-RT group. The 5-year BCSS was $98.85 \%$ (95\% $\mathrm{Cl}, 98.24-99.25 \%)$ in RT group and $94.93 \%$ (95\% Cl, 93.46-96.08\%) in non-RT group. The 10-year BCSS was $95.96 \%(95 \% \mathrm{Cl}, 94.66-96.95 \%)$ in RT group and $94.93 \%(95 \% \mathrm{Cl}, 0.93 .46-96.08 \%)$ in non-RT group. The 15 -year BCSS rate was $93.82 \%(95 \% \mathrm{Cl}$, 91.75-95.38\%) in RT group and $92.02 \%(95 \% \mathrm{Cl}, 89.39-94.03 \%)$ in non-RT group. The univariate analyses also confirmed that the RT group indicated a significantly favorable prognosis $(\mathrm{HR}, 0.71 ; 95 \% \mathrm{Cl}, 0.51$ to 0.99; $P=0.041$ ). After adjusted age, race, marital status and tumor size, the result of multivariable Cox analysis did not change substantially (adjusted $\mathrm{HR}, 0.66 ; 95 \% \mathrm{Cl}, 0.47$ to $0.92 ; P=0.014$ ).

The salutary effect of adjuvant RT on BCSS was further assessed in different subgroups among the matched population who underwent lumpectomy, and the HR interactions were tested(Fig. 4). The benefit of RT seemed to be significant in some patients. The HR was $0.64(95 \% \mathrm{Cl}, 0.43$ to 0.95$)$ for patients aged 70 years and older, $0.44(95 \% \mathrm{Cl}, 0.24$ to 0.81$)$ for married women, $0.44(95 \% \mathrm{Cl}, 0.27$ to 0.71$)$ for patients with $1.1-2.0 \mathrm{~cm}$ tumor size, $0.63(95 \% \mathrm{Cl}, 0.44$ to 0.91$)$ for patients with positive ER disease, $0.60(95 \% \mathrm{Cl}$, 
0.40 to 0.90 ) for patients with positive PR tumor, 0.31 ( $95 \% \mathrm{Cl}, 0.10$ to 0.96$)$ for patients diagnosed during 2010-2015. However, as we can see from the Fig. 4, there were no statistically significance in global test for interaction $(P>0.05)$.

\section{Discussion}

Among women with early-stage breast cancer receiving lumpectomy, the addition of RT is a standardized treatment based not only on its benefit in reducing ipsilateral breast cancer recurrence, but also on its ability to significantly improve BCSS $(25,26)$. Nevertheless, the magnitude of the effect of adjuvant RT in PMBC patients has not been clearly quantified because of its relatively favorable behaviors and prognosis. In this large population-based study, by using matched approach among patients who received lumpectomy with $\mathrm{T} 1-2 \mathrm{NOMO}(\mathrm{T} \leq 3 \mathrm{~cm}) \mathrm{PMBC}$, our result clearly indicated that adjuvant irradiation following lumpectomy was significantly associated with BCSS benefit.

In the cohort, the cumulative 15-year BCSS rate was $94.39 \%$ for women with PMBC received adjuvant RT after lumpectomy, and $91.38 \%$ for patients treated with lumpectomy alone $(\mathrm{HR}=0.52 ; 95 \% \mathrm{Cl}, 0.40$ to $0.67 ; P<0.001$; Table 2). After adjustment for potential confounding factors, it was translated that the relative reduction of breast cancer-special death was $34 \%$, and the absolute risk reduction at 15 years was $1.8 \%$. On average, 55 women would need to be treated with RT to save 1 life. In addition, heterogeneity tests of the interaction term were not significant among the matched population, suggesting that the protective prognostic value of adjuvant RT were consistent across different populations.

Our research has several potential strengths. To our best knowledge, this is a large cohort used to evaluate the effect on postoperative RT following lumpectomy among patients with early-stage PMBC. Our study only aims to patient with tumor size less than $3 \mathrm{~cm}$, which minimizes the impact of endocrine therapy on results. PSM was generated to eliminate the confounding factors, leading to the baseline was comparable between treatment groups. In addition, the heterogeneity of RT effect was tested in subgroup interaction, which further verified the benefit of BCSS was attributable to radiotherapy rather than a baseline imbalance in clinicopathologic features.

Only a few studies have assessed the role of postoperative RT in this special type of breast cancer. Histological types of breast cancer, as prognostic risk factors, have rarely been evaluated in randomized trials related to radiation therapy(27). Single-center experiences did not demonstrate that adjuvant RT increased recurrence/metastasis-free survival (RFS) among patient with PMBC(11). In several retrospective studies, they were also failed to show that receiving adjuvant RT could improve the OS or DFS in $\operatorname{PMBC}(1,3,6,11,19,28,29)$. A previous SEER analysis including 11422 patients with PMBC between 1973 and 2002, with a mean follow-up period of 84 months, showed that the addition of radiotherapy was not significantly asscosiated with prognosis using multivariable Cox regression analysis(3). Here, we assessed BCSS benefit of adjuvant RT following lumpectomy compared with lumpectomy alone in T1-2NOM0(tumor size $\leq 3 \mathrm{~cm}$ ) PMBC by using PSM method and multivariable Cox 
regression analysis (adjust $\mathrm{HR}=0.66 ; 95 \% \mathrm{Cl}, 0.47$ to $0.92 ; \mathrm{P}=0.014$; Table 4). Combined with the above, we believe that adjuvant RT is a value option for patients underwent lumpectomy with PMBC, even in those with low-risk factors.

Table 4.Univariate and multivariate prognostic analyses of BCSS after PSM. 


\begin{tabular}{|c|c|c|c|c|c|c|}
\hline \multirow[t]{2}{*}{ Characteristics } & \multicolumn{3}{|c|}{ Univariate } & \multicolumn{3}{|c|}{ multivariate } \\
\hline & $\mathrm{HR}$ & $95 \% \mathrm{Cl}$ & $P$ & aHR & $95 \% \mathrm{Cl}$ & $P$ \\
\hline \multicolumn{7}{|c|}{ Treatment groups } \\
\hline Non-RT & 1.00 & & & 1.00 & & \\
\hline RT & 0.71 & $0.51-0.98$ & 0.039 & 0.66 & $0.47-0.92$ & 0.014 \\
\hline \multicolumn{7}{|c|}{ Age of diagnosis, years } \\
\hline$<50$ & 1.00 & & & 1.00 & & \\
\hline $50-59$ & 0.81 & $0.30-2.17$ & 0.678 & 0.91 & $0.34-2.45$ & 0.919 \\
\hline $60-69$ & 1.52 & $0.68-3.39$ & 0.311 & 1.71 & $0.75-3.88$ & 0.152 \\
\hline$\geq 70$ & 2.73 & $1.32-5.62$ & 0.006 & 2.83 & $1.32-6.05$ & 0.002 \\
\hline \multicolumn{7}{|l|}{ Era of diagnosis } \\
\hline 1998-2004 & 1.00 & & & & & \\
\hline 2005-2009 & 1.02 & $0.70-1.50$ & 0.902 & & & \\
\hline 2010-2015 & 0.87 & $0.48-1.57$ & 0.649 & & & \\
\hline \multicolumn{7}{|l|}{ Race } \\
\hline White & 1.00 & & & 1.00 & & \\
\hline Black & 1.60 & $0.99-2.61$ & 0.055 & 1.67 & $1.02-2.74$ & 0.042 \\
\hline Other & 0.55 & $0.26-1.19$ & 0.130 & 0.68 & $0.31-1.47$ & 0.325 \\
\hline \multicolumn{7}{|l|}{ Marital status } \\
\hline Married & 1.00 & & & 1.00 & & \\
\hline Non-married & 1.18 & $0.62-2.22$ & 0.614 & 1.18 & $0.62-2.25$ & 0.620 \\
\hline DSW & 2.14 & $1.48-3.08$ & $<.001$ & 1.60 & $1.10-2.35$ & 0.015 \\
\hline Unknown & 1.99 & $0.94-4.22$ & 0.072 & 1.66 & $0.78-3.52$ & 0.189 \\
\hline \multicolumn{7}{|l|}{ Laterality } \\
\hline Left & 1.00 & & & & & \\
\hline Right & 1.03 & $0.74-1.42$ & 0.879 & & & \\
\hline \multicolumn{7}{|c|}{ Tumor size ( $T$ stage), cm } \\
\hline$\leq 1.0(\mathrm{~T} 1)$ & 1.00 & & & 1.00 & & \\
\hline 1.1-2.0 (T1) & 2.09 & $1.38-3.18$ & 0.001 & 2.19 & $1.44-3.33$ & $<.001$ \\
\hline
\end{tabular}




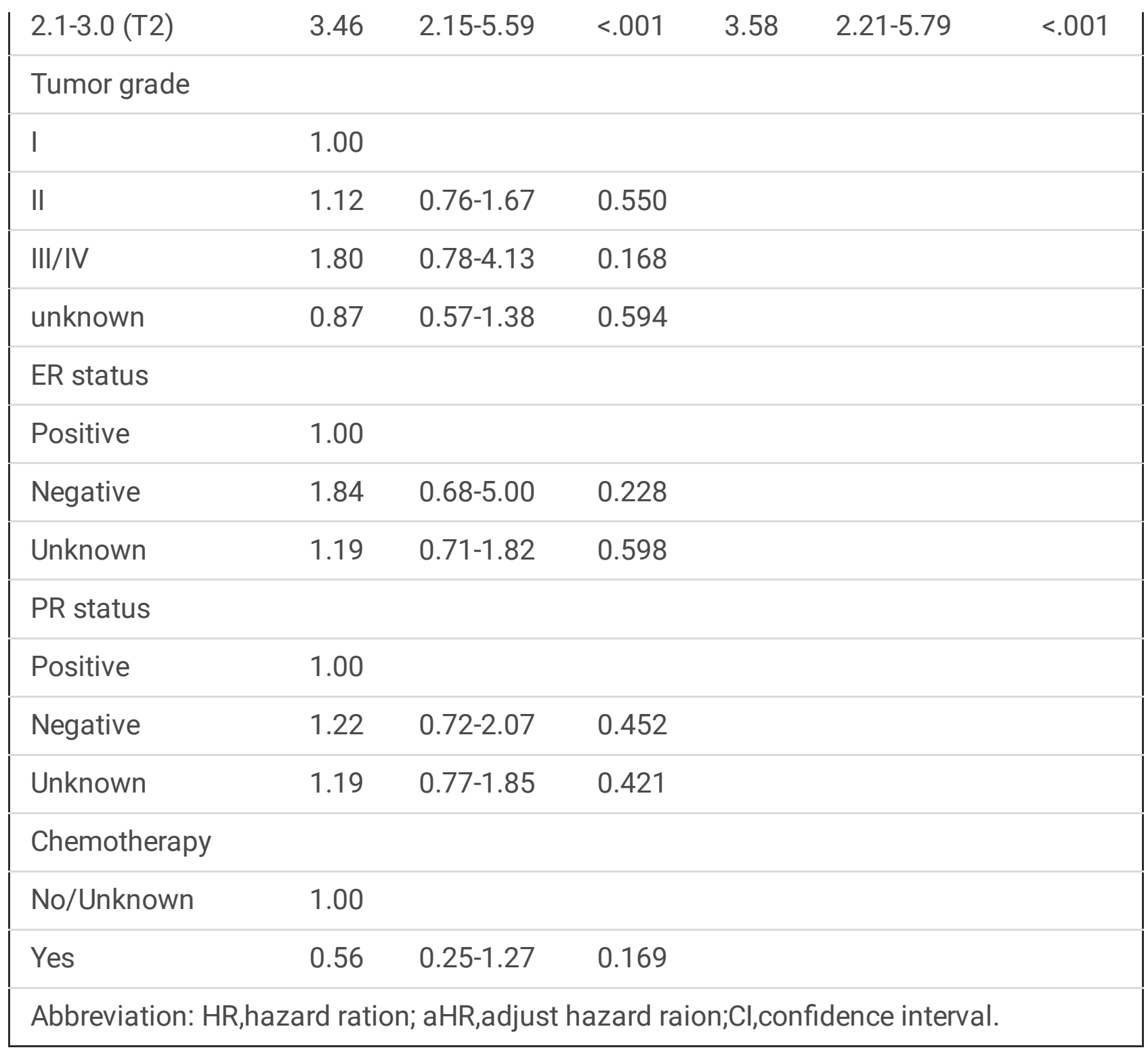

In the cohort, the risk prediction stratified score basing on clinical features and molecular biomarkers is low among patients with PMBC, which might explain why absolute reductions in 15-year risk of breast cancer death tend to be modest. Besides, we believe patterns of intrinsic tumorigenesis of PMBC may contribute to the result. This special type of breast cancer is distinct from other ER-positive/HER2negative form of breast cance in terms of the tumorigenicity of mutated genes $(5,16)$, suggesting that the genomic profiling of unusual variants of breast cancer should be taken into account in developing suitable personalized management for patients. Meanwhile, it is doubtful whether the modest benefit is worth tolerating radiation treatment-indued adverse events. Late toxicity for normal tissues impaired quality of life. Potential radiation-related cardiac toxicity and an additional second cancer risk threaten to roll back life expectancy(30-33). In the future, for those with specific types of breast cancer, it is required to further study the prediction of clinical benefit from radiation therapy, and the identification of low-risk patients in whom radiation can be safely omitted.

Nevertheless, we must acknowledge several limitations of this study. There are inherent biases in retrospective study inevitably. The SEER database at present cannot provide the code on surgical 
margins, lymphovascular invasion, Ki-67 and hormone therapy. Data are missing in some cases for fundamental variables such as tumor size, grade, TNM stage, hormone receptor status. Fortunately, missing data in TNM stage and tumor size did not have an impact on the study. It was reported that the utilization of radiotherapy was under reported in SEER database(34). The radiotherapy treatment was not assigned at random. Although the propensity score matching method is efficient for reducing the confounding bias, a significant proportion of samples are censored in the paired matching process.

\section{Conclusion}

In patients with localized PMBC receiving lumpectomy, our results indicated that the management with adjuvant RT slightly improved BCSS compared with its omission. The adjvuant radiotherapy is an appropriate therapeutic option for patients received lumpectomy with localized PMBC.

\section{Abbreviations}

Pure mucinous breast cancer (PMBC); postoperative radiotherapy (RT); the Surveillance, Epidemiology, and End Results database (SEER); Breast cancer-specific survival (BCSS); Propensity score matching (PSM); Mucinous breast carcinoma (MBC); mix mucinous breast carcinoma (MMBC); progesterone receptor(PR); estrogen receptor(ER); human epidermal growth factors 2 (HER-2); disease-free survival (DFS);overall survival(OS);American Joint Committee on Cancer (AJCC);Hazard Ratio (HR); 95\% confidence interval $(95 \% \mathrm{Cl})$.

\section{Declarations}

\section{Ethical Approval and Consent to participate}

Not applicable.

\section{Consent for publication}

Not applicable.

\section{Availability of supporting data}

Any request of supporting data may be sent to the corresponding author.

\section{Conflict of interest statement}

The authors declare that the research was conducted in the absence of any commercial or financial relationships that could be construed as a potential conflict of interest.

\section{Funding}


This work was supported by the Zhejiang Provincial Natural Science Foundation of Chian (grant no.Y19H160283).

\section{Author contribution statement}

MQP contributed to study conception and design, data collection and analysis, manuscript writing. WYZ wrote and edited the manuscript. SJL,WXC reviewed the manuscript.WXC acquired the funding. All authors contributed to the submitted version. MQP, WYZ and SJL have contributed equally to this work and share first authorship.

\section{Authors' information}

${ }^{1}$ Department of Breast Surgery, Zhejiang Provincial People's Hospital, People's Hospital of Hangzhou Medical College, Hangzhou, Zhejiang, China.

${ }^{2}$ Department of Breast Surgery, Second Affiliated Hospital, Zhejiang University School of Medicine, Hangzhou, Zhejiang, China.

${ }^{3}$ Department of Breast Surgery, Ninghai Maternal and Child Health Care Hospital, Ningbo, Zhejiang, China.

${ }^{4}$ Department of Breast Surgery, Women's Hospital, Zhejiang University School of Medicine, Hangzhou, Zhejiang, China.

\section{References}

1. Diab SG, Clark GM, Osborne CK, Libby A, Allred DC, Elledge RM. Tumor characteristics and clinical outcome of tubular and mucinous breast carcinomas. J Clin Oncol (1999) 17(5):1442-8. Epub 1999/05/20. doi: 10.1200/jco.1999.17.5.1442. PubMed PMID: 10334529.

2. The world Health Organization Histological Typing of Breast Tumors-Second Edition. The World Organization. American journal of clinical pathology (1982) 78(6):806-16. Epub 1982/12/01. doi: 10.1093/ajcp/78.6.806. PubMed PMID: 7148748.

3. Di Saverio S, Gutierrez J, Avisar E. A retrospective review with long term follow up of 11,400 cases of pure mucinous breast carcinoma. Breast Cancer Res Treat (2008) 111(3):541-7. Epub 2007/11/21. doi: 10.1007/s10549-007-9809-z. PubMed PMID: 18026874.

4. Lei L, Yu X, Chen B, Chen Z, Wang X. Clinicopathological Characteristics of Mucinous Breast Cancer: A Retrospective Analysis of a 10-Year Study. Plos One (2016) 11(5). doi: 10.1371/journal.pone.0155132. PubMed PMID: WOS:000376883000002.

5. Lacroix-Triki M, Suarez PH, MacKay A, Lambros MB, Natrajan R, Savage K, et al. Mucinous carcinoma of the breast is genomically distinct from invasive ductal carcinomas of no special type. The Journal of 
pathology (2010) 222(3):282-98. Epub 2010/09/04. doi: 10.1002/path.2763. PubMed PMID: 20815046.

6. Bae SY, Choi MY, Cho DH, Lee JE, Nam SJ, Yang JH. Mucinous carcinoma of the breast in comparison with invasive ductal carcinoma: clinicopathologic characteristics and prognosis. Journal of breast cancer (2011) 14(4):308-13. Epub 2012/02/11. doi: 10.4048/jbc.2011.14.4.308. PubMed PMID: 22323918; PubMed Central PMCID: PMCPMC3268928.

7. Thurman SA, Schnitt SJ, Connolly JL, Gelman R, Silver B, Harris JR, et al. Outcome after breastconserving therapy for patients with stage I or II mucinous, medullary, or tubular breast carcinoma. International journal of radiation oncology, biology, physics (2004) 59(1):152-9. Epub 2004/04/20. doi: 10.1016/j.ijrobp.2003.10.029. PubMed PMID: 15093911.

8. Anderson WF, Pfeiffer RM, Dores GM, Sherman ME. Comparison of age distribution patterns for different histopathologic types of breast carcinoma. Cancer epidemiology, biomarkers \& prevention : a publication of the American Association for Cancer Research, cosponsored by the American Society of Preventive Oncology (2006) 15(10):1899-905. Epub 2006/10/13. doi: 10.1158/1055-9965.epi-06-0191. PubMed PMID: 17035397.

9. Skotnicki P, Sas-Korczynska B, Strzepek L, Jakubowicz J, Blecharz P, Reinfuss M, et al. Pure and Mixed Mucinous Carcinoma of t: A Comparison of Clinical Outcomes and Treatment Resultshe Breast. Breast Journal (2016) 22(5):529-34. doi: 10.1111/tbj.12621. PubMed PMID: WOS:000383520200006.

10. Wasif N, McCullough AE, Gray RJ, Pockaj BA. Influence of uncommon histology on breast conservation therapy for breast cancer-biology dictates technique? Journal of Surgical Oncology (2012) 105(6):586-90. doi: 10.1002/jso.22132. PubMed PMID: WOS:000302550200012.

11. Cao AY, He M, Liu ZB, Di GH, Wu J, Lu JS, et al. Outcome of pure mucinous breast carcinoma compared to infiltrating ductal carcinoma: a population-based study from China. Annals of surgical oncology (2012) 19(9):3019-27. Epub 2012/03/28. doi: 10.1245/s10434-012-2322-6. PubMed PMID: 22451233.

12. Louwman MW, Vriezen M, van Beek MW, Nolthenius-Puylaert MC, van der Sangen MJ, Roumen RM, et al. Uncommon breast tumors in perspective: incidence, treatment and survival in the Netherlands. International journal of cancer (2007) 121(1):127-35. Epub 2007/03/03. doi: 10.1002/ijc.22625. PubMed PMID: 17330844.

13. Fu J, Wu L, Jiang M, Li D, Jiang T, Hong Z, et al. Clinical Nomogram for Predicting Survival Outcomes in Early Mucinous Breast Cancer. Plos One (2016) 11(10). doi: 10.1371/journal.pone.0164921. PubMed PMID: WOS:000386204000065.

14. Ishikawa T, Hamaguchi Y, Ichikawa Y, Shimura M, Kawano N, Nakatani Y, et al. Locally advanced mucinous carcinoma of the breast with sudden growth acceleration: a case report. Japanese journal of 
clinical oncology (2002) 32(2):64-7. Epub 2002/04/12. doi: 10.1093/jjco/hyf012. PubMed PMID: 11948231.

15. Fujii H, Anbazhagan R, Bornman DM, Garrett ES, Perlman E, Gabrielson E. Mucinous cancers have fewer genomic alterations than more common classes of breast cancer. Breast Cancer Research and Treatment (2002) 76(3):255-60. doi: 10.1023/a:1020808020873. PubMed PMID:

WOS:000178929800008.

16. Pareja F, Lee JY, Brown DN, Piscuoglio S, Gularte-Merida R, Selenica P, et al. The Genomic Landscape of Mucinous Breast Cancer. Journal of the National Cancer Institute (2019). doi: 10.1093/jnci/djy216. PubMed PMID: MEDLINE:30649385.

17. Rasmussen BB, Rose $\mathrm{C}$, Christensen IB. Prognostic factors in primary mucinous breast carcinoma. American journal of clinical pathology (1987) 87(2):155-60. Epub 1987/02/01. doi:

10.1093/ajcp/87.2.155. PubMed PMID: 3028120.

18. Avisar E, Khan MA, Axelrod D, Oza K. Pure mucinous carcinoma of the breast: a clinicopathologic correlation study. Annals of surgical oncology (1998) 5(5):447-51. Epub 1998/08/26. PubMed PMID: 9718175.

19. Gwark SC, Lee HS, Lee Y, Lee SB, Sohn G, Kim J, et al. Clinical Implication of HER2 Status in Hormone Receptor-Positive Mucinous Breast Cancer. Annals of surgical oncology (2019) 26(7):2166-74. Epub 2019/04/13. doi: 10.1245/s10434-019-07332-9. PubMed PMID: 30977015.

20. Ding S, Wu J, Lin C, Chen W, Li Y, Shen K, et al. Predictors for Survival and Distribution of 21-Gene Recurrence Score in Patients With PureMucinous Breast Cancer: A SEER Population-Based Retrospective Analysis. Clinical breast cancer (2018). doi: 10.1016/j.clbc.2018.10.001. PubMed PMID:

MEDLINE:30396812.

21. Wu SG, Li FY, Wang J, Lian CL, Zhou J, He ZY. Omission of adjuvant radiotherapy following breastconserving surgery for elderly women with early-stage pure mucinous breast carcinoma. Radiation oncology (London, England) (2019) 14(1):190. Epub 2019/11/07. doi: 10.1186/s13014-019-1394-x. PubMed PMID: 31685005; PubMed Central PMCID: PMCPMC6829954.

22. National Cancer Institute: Surveillance, Epidemiology, and End Results. Available from: https://seer.cancer.gov/.

23. Iwamoto T, Booser D, Valero V, Murray JL, Koenig K, Esteva FJ, et al. Estrogen receptor (ER) mRNA and ER-related gene expression in breast cancers that are $1 \%$ to $10 \%$ ER-positive by immunohistochemistry. $J$ Clin Oncol (2012) 30(7):729-34. Epub 2012/02/01. doi: 10.1200/jco.2011.36.2574. PubMed PMID: 22291085. 
24. Hammond ME, Hayes DF, Dowsett M, Allred DC, Hagerty KL, Badve S, et al. American Society of Clinical Oncology/College Of American Pathologists guideline recommendations for immunohistochemical testing of estrogen and progesterone receptors in breast cancer. J Clin Oncol (2010) 28(16):2784-95. Epub 2010/04/21. doi: 10.1200/jco.2009.25.6529. PubMed PMID: 20404251; PubMed Central PMCID: PMCPMC2881855.

25. Clarke M, Collins R, Darby S, Davies C, Elphinstone P, Evans V, et al. Effects of radiotherapy and of differences in the extent of surgery for early breast cancer on local recurrence and 15-year survival: an overview of the randomised trials. Lancet (London, England) (2005) 366(9503):2087-106. Epub 2005/12/20. doi: 10.1016/s0140-6736(05)67887-7. PubMed PMID: 16360786.

26. Darby S, McGale P, Correa C, Taylor C, Arriagada R, Clarke M, et al. Effect of radiotherapy after breastconserving surgery on 10-year recurrence and 15-year breast cancer death: meta-analysis of individual patient data for 10,801 women in 17 randomised trials. Lancet (London, England) (2011) 378(9804):1707-16. Epub 2011/10/25. doi: 10.1016/s0140-6736(11)61629-2. PubMed PMID: 22019144; PubMed Central PMCID: PMCPMC3254252.

27. Liljegren G, Holmberg L, Bergh J, Lindgren A, Tabar L, Nordgren H, et al. 10-Year results after sector resection with or without postoperative radiotherapy for stage I breast cancer: a randomized trial. $J$ Clin Oncol (1999) 17(8):2326-33. Epub 1999/11/24. doi: 10.1200/jco.1999.17.8.2326. PubMed PMID: 10561294.

28. Pan B, Yao R, Shi J, Xu Q-Q, Zhou Y-D, Mao F, et al. Prognosis of subtypes of the mucinous breast carcinoma in Chinese women: a population-based study of 32-year experience (1983-2014). Oncotarget (2016) 7(25):38864-75. doi: 10.18632/oncotarget.8778. PubMed PMID: WOS:000378229100116.

29. Vo T, Xing Y, Meric-Bernstam F, Mirza N, Vlastos G, Symmans WF, et al. Long-term outcomes in patients with mucinous, medullary, tubular, and invasive ductal carcinomas after lumpectomy. Am J Surg (2007) 194(4):527-31. Epub 2007/09/11. doi: 10.1016/j.amjsurg.2007.06.012. PubMed PMID: 17826073.

30. Hopwood P, Haviland JS, Sumo G, Mills J, Bliss JM, Yarnold JR. Comparison of patient-reported breast, arm, and shoulder symptoms and body image after radiotherapy for early breast cancer: 5-year follow-up in the randomised Standardisation of Breast Radiotherapy (START) trials. The Lancet Oncology (2010) 11(3):231-40. Epub 2010/02/09. doi: 10.1016/s1470-2045(09)70382-1. PubMed PMID: 20138809.

31. Darby SC, Ewertz M, McGale P, Bennet AM, Blom-Goldman U, Bronnum D, et al. Risk of ischemic heart disease in women after radiotherapy for breast cancer. The New England journal of medicine (2013) 368(11):987-98. Epub 2013/03/15. doi: 10.1056/NEJMoa1209825. PubMed PMID: 23484825.

32. Haviland JS, Owen JR, Dewar JA, Agrawal RK, Barrett J, Barrett-Lee PJ, et al. The UK Standardisation of Breast Radiotherapy (START) trials of radiotherapy hypofractionation for treatment of early breast 
cancer: 10-year follow-up results of two randomised controlled trials. The Lancet Oncology (2013) 14(11):1086-94. Epub 2013/09/24. doi: 10.1016/s1470-2045(13)70386-3. PubMed PMID: 24055415.

33. Grantzau T, Overgaard J. Risk of second non-breast cancer after radiotherapy for breast cancer: a systematic review and meta-analysis of 762,468 patients. Radiotherapy and oncology : journal of the European Society for Therapeutic Radiology and Oncology (2015) 114(1):56-65. Epub 2014/12/03. doi: 10.1016/j.radonc.2014.10.004. PubMed PMID: 25454172.

34. Walker GV, Giordano SH, Williams M, Jiang J, Niu J, MacKinnon J, et al. Muddy water? Variation in reporting receipt of breast cancer radiation therapy by population-based tumor registries. International journal of radiation oncology, biology, physics (2013) 86(4):686-93. Epub 2013/06/19. doi: 10.1016/j.jjrobp.2013.03.016. PubMed PMID: 23773392; PubMed Central PMCID: PMCPMC3836610.

\section{Figures}


SEER Database 1998-2015

Female, diagnosis as first primary PMBC, with positive histology

Diagnosed from death certificate or autopsy only; uncomplete follow-up data $(n=1166)$

Distance metastasis/unknown M stage $(\mathrm{n}=259)$ node involvement/unknown N stage $(\mathrm{n}=2010)$

T3/4 stage/unknown T stage $(n=498)$

Tumor size $>3 \mathrm{~cm} /$ unknown size $(\mathrm{n}=1179)$

Unknown laterality or paired side $(n=1)$

Did not undergo lumpectomy $(\mathrm{n}=3258)$

The sequence of beam RT was not following lumpectomy $(\mathrm{n}=532)$

Patients with T1-2N0M0 (tumor size $\leq 3 \mathrm{~cm}$ ) who received postoperative RT or no RT following lumpectomy

$$
(n=7846)
$$

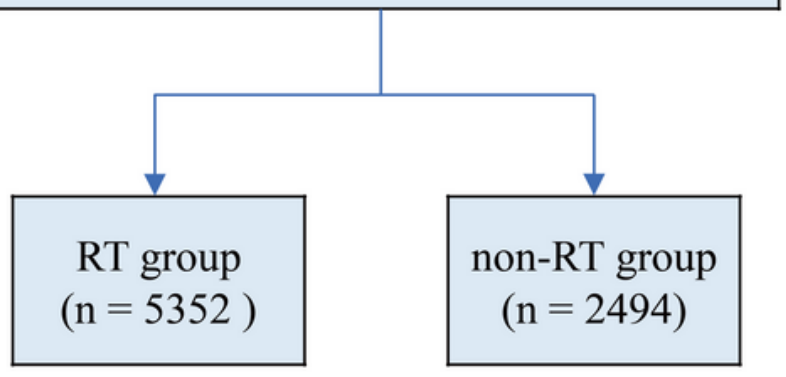

\section{Figure 1}

Patient selection diagram. 


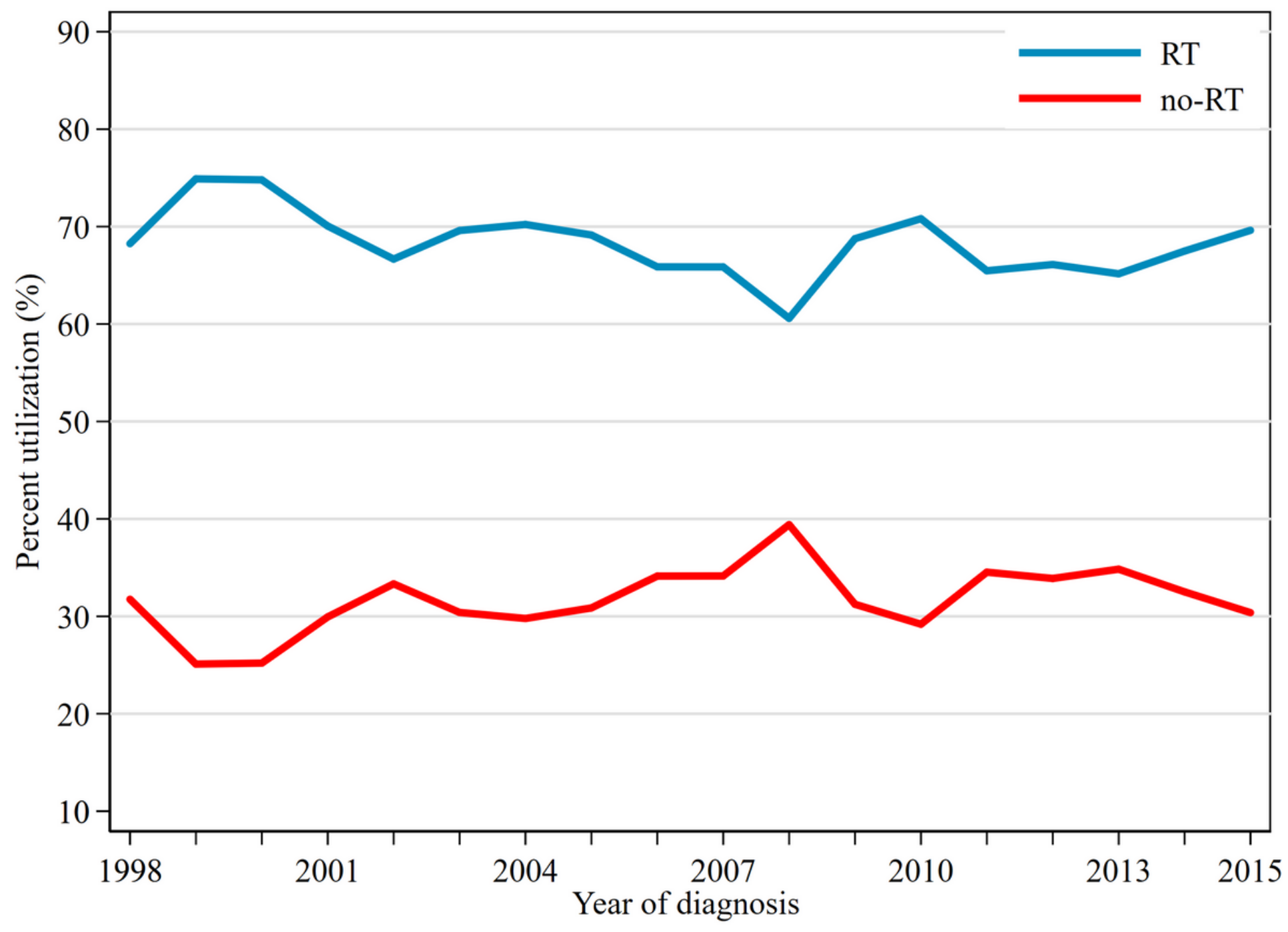

Figure 2

Utilization of postoperative radiotherapy versus omission over time in patients with T1-2NOMO(tumor size $\leq 3 \mathrm{~cm})$ PMBC from SEER Database, 1998-2015.
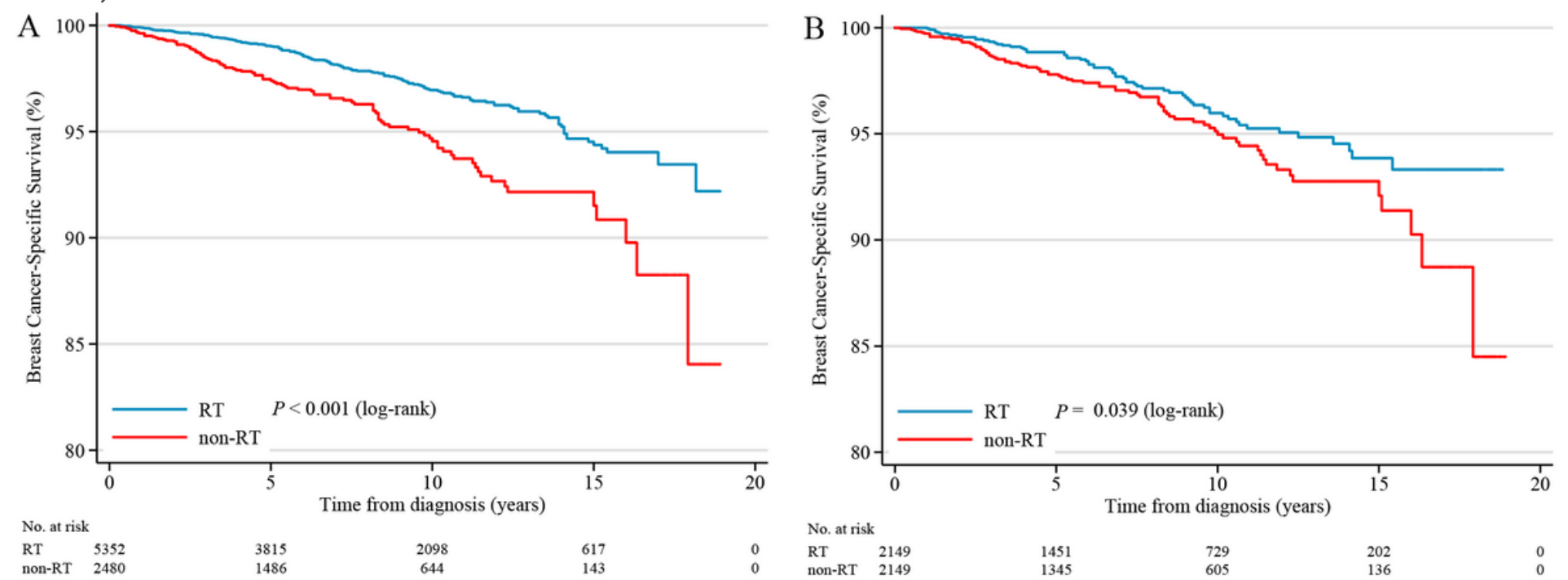

RT 5352

1486

644

No. at risk

$\begin{array}{ll}\text { RT } & 2149 \\ \text { non-RT } & 2149\end{array}$

1451
1345

729
605

202
136 
Figure 3

Kaplan-Meier curves comparing BCSS between treatment groups for A) all patients; B) propensitymatched patients.

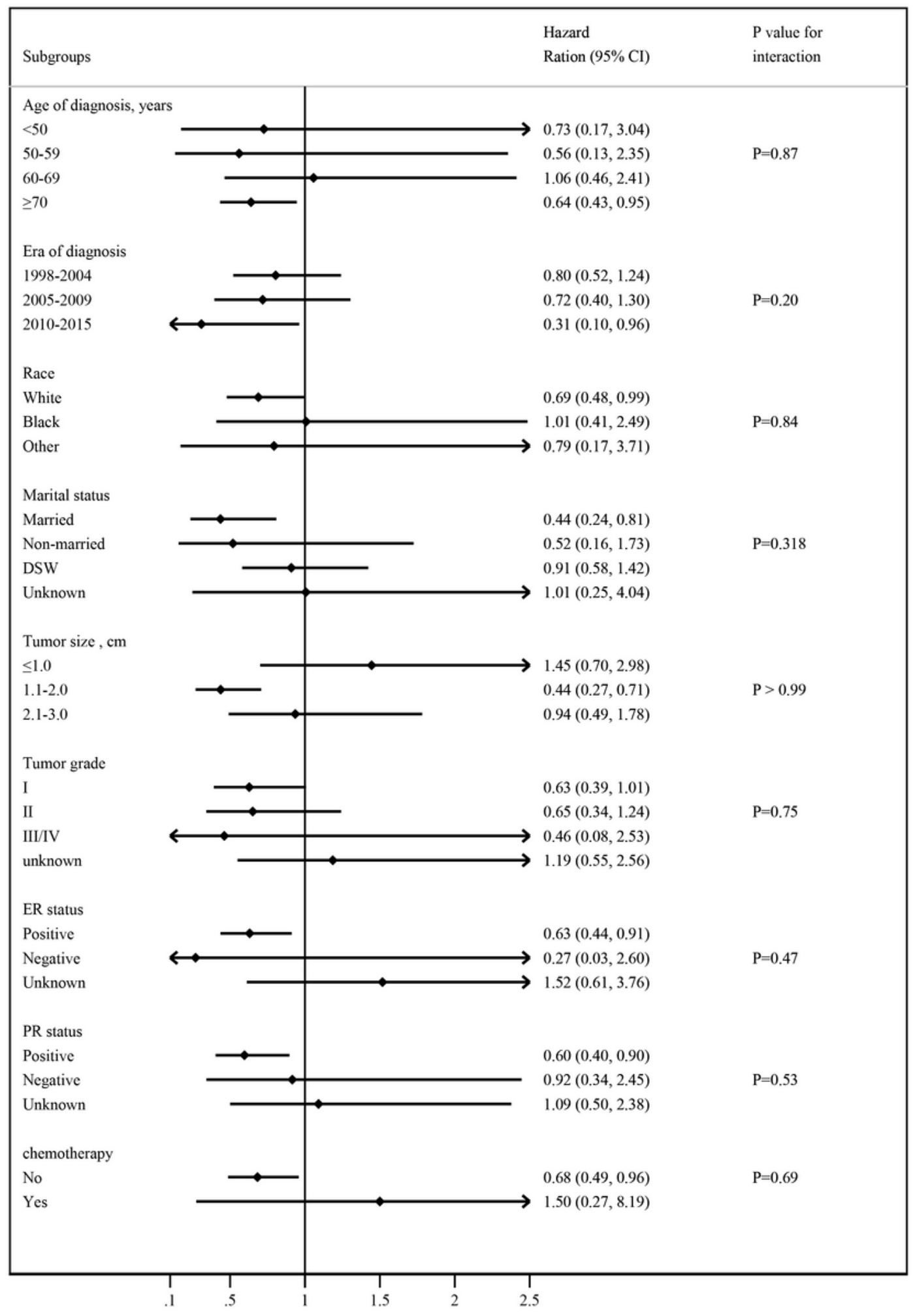

Figure 4 
Forest plot depicting hazard ratios of adjuvant radiotherapy following lumpectomy versus lumpectomy alone for early-stage PMBC in the propensity-matched population. 